UC-4

Reporting Date: February 1976 Issued: April 1976

\title{
The Crystal Structures of Cerium Metal at High Pressure
}

by

W. H. Zachariasen*

F. H. Ellinger*

"Consultants to LASL Group CMB-5.

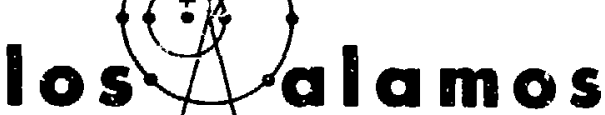

scientific laboralory

of the University of California

lO5 ALAMOS, NEW MEXICO 87545

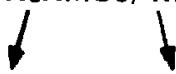

An Affirmative Action/Equal Opporlunity Employer 
This work was perforned under : -uspices of the US Energy Research and Development Administration and the University of Chicago.

Printed in the United States of Amencas. 2vailuble from National Technical Intormation Service

U.S. Department of Commerce

5285 Port Roya! Roud

Springtield, VA 22161

Price: Printed Copy $\$ 3.50$ Microtiche \$2.25

This report was urepured es sn arrount of work sponsared

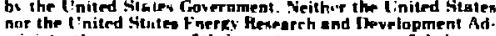

miristrution, nor env of their emplayess, nnr env of their con.

15arlors. suleronirertora, or thrir employess. makes any

warrantv express or ims'ied, or assumes a ny lekal tiebility ar

responsibility for the eceuracv, completeness, or usefulness of

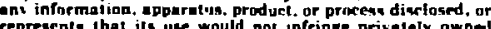

rixhts. 


\title{
THE CRYSTAL STRUCTURES OF CERIUM METAL AT HIGH PRESSURE
}

by

\author{
W. H. Zachariasen and F. H. Ellinger
}

\begin{abstract}
The high pressure form of cerium metal stable above 51 kbar, $\alpha$ $C e$, is found to be orthorhombic with the $\alpha$ - $U$ type of structure. At 58 kbar the cell dimensions of $\alpha^{\prime}-C e$ are: $a=3.049 \AA, b=5.998 \AA, c$ $=\mathbf{5} .215 \AA$. A second, metastable phase of cerium metal, $\alpha$ "-Ce, has also been observed. It is monoclinic body-centered with a deformed, face-centered cubic (fcc) structure. The cell dimensions of $\alpha$ "-Ce at 56 kbar are: $a=4.762 \AA, b=3.170 \AA, c=3.169 \AA, \beta=91.73^{\circ}$. The volume change at the $\alpha-\alpha^{\prime}$ transition point is $\Delta V / V=0.011$. Cerium metal is fully tetravalent in both $\alpha^{\prime}-\mathrm{Ce}$ and $\alpha^{\prime \prime}-\mathrm{Ce}$.
\end{abstract}

\section{INTRODUCTION}

This report describes the resulis of in situ $x$-ray diffraction studies of ceriun! metal at pressures up to - 100 kbar. All observations were made at room temperature. A preliminary report of our tindings was published two years ago.:

The form if cerium metal at room pressure and temperature. ;-Ce. as shown by Lawson and Tang."is transformed into $a-\mathrm{Ce}$ at $\sim 8$ kbar. This transformation is of unique type: both phases have the foc structure. but the solume reduction is unusually large. $\Delta V / N=0.148 \pm 0.003$. Zachariasen suggested that this volume collapse was due to electron promotion from the $4 f$ to the valence shell. 3

A number of investigators have observed a second phase transformation $a \cdot \sigma \alpha$ in cerium metal. The transformation pressure has been reported to be 91 kbar by Bridgman. 400 to 65 kbal by Stager and Drickamer. 50 kbar by Wittig. ${ }^{6} 56 \mathrm{kbar}$ by King et al., ${ }^{7}$ and 51 kbar by Schaufelberger and Merx." Witt ig reported that ${ }^{\prime}$-Ce becomes superconducting below $1.7 \mathrm{~K}$.

According to Franceschi and Olcese. ${ }^{9}$ "-Ce has the fice structure with a unit cell edge $a=4.66 \pm 0.01$ A which remains unchanged from 50 to 80 kbar. McWhan. 1 "on the other hand. found that $\alpha$ ' -Ce has the hexagonal close-packed (hcp) st ructure wit h cell constants $\mathrm{a}=3.16 \pm 0.01 \AA . \mathrm{c}=\mathbf{0} .20 \pm 0.02 \AA$ at -65 kbar. Our preliminary publication ${ }^{1}$ reports the existence of two high pressure phases, a ${ }^{\prime}-\mathrm{Ce}$ and $a "$ Ce. $a^{\prime}$-Ce was found to have the a-L type of structure. whereas " budy-centered with just two atoms per unit cell. The cell constants were reported to be:

1'-Ce at 66 hbar:

$$
\begin{aligned}
& a=3.06 \pm 0.01 \AA \\
& b=6.01 \pm 0.01 \AA \\
& c=5.23 \pm 0.01 \AA
\end{aligned}
$$

"'-Ce at 56 khar:

$$
\begin{aligned}
& \mathrm{a}=4.79 \pm 0.02 \AA \\
& \mathrm{b}=3.20 \pm 0.01 \AA \\
& \mathrm{c}=3.18 \pm 0.01 \AA \\
& i=92.1 \pm 0.2^{\circ}
\end{aligned}
$$

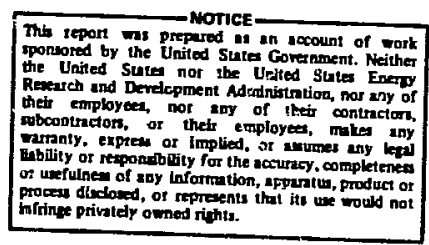

Schaufelberger and Merx ${ }^{\not}$ state that ${ }^{\prime}-\mathrm{Ce}$ is a mixture of isodensity. icc and hep phases and possibly a third. metastable component.

In view of the conflicting findings of the various investigators it sems necessary to present the interpretation of our $x$-ray diffract ion data in some cetail. 


\section{Ii. EXPERIMENTAL PROCEDURE}

The diffraction patterns of cerium metal were obrained with diamond-anvil equipment of the type described by Basiett. Takahashi, and Stook." using filtered Moku radiation. The bean incident upon the sample had a diameter of $109 \mu$, and the pressure gradient in the irradiated part of the specimen was negligible. Because of the traismission method used in the experiments, absurption increased rapidly with scatterinr angle. and it was rarely possible to measure diffraction lines beyond $2 \|=40^{\circ}$.

With our equipment it was difficult to measure the pressures at which the diffraction patterns were taken. Indeed. the pressures given in Ref. 1 are $(0)$ high by 10 to 12 kbar. In th!s seport it will be assumed that the $1-1 \cdot$ transition occurs at $51 \pm 1$ kbar as fiund by schaufelberger and Merx. and further that the lat tice constant of a-Ce in the range 18 to 51 kbar varies with pressure as found by these investigators. For pressures above $\mathrm{il}$ kbar we have assumed that the atomic volume of $\mathrm{a}^{\prime \prime}-\mathrm{Ce}$ is 23.91 $\AA: 1$ at $56 \mathrm{kbar}, 22.22 \AA^{3}$ at $100 \mathrm{kbar}$. and that the comeressibility of " "Ce is constant. The resulting pressurs: calibration in terms of the atomic volumes of $"$ - $-\mathrm{Ce}$ and $"$ " -Ce is shown in Table I. According to this table. Franceschi and Olcese's experiments were carried out at effective pressure no exceeding 35 kbar. i.e.. well below the a-ti tran-ition.

Six difterent samples of cerium metal were used in the investigation: four of them were slices cut from the same piece of $L$. S. Bureau of Mines high-purity electrolytic metal. More than $90 \mathrm{x}$-ray diffraction patterns were taken in the course of the study. Diffraction data are given in the tables as $S \equiv 10^{-4} \sin ^{2}=1$ with intensities listed as very strong (vs). strong (s). medium ( $m$ ), weak ( $w$ ), very weak ( $(w)$, trace $(t)$ : the $5 y m b o l D$ indicates a diffuse or unresolved double line. Except for very weak diffraction lines the maximum error in measured $S$-values is \pm 1 for $S=$ 100 and \pm .3 for $S=1000$.

Attempts to interpret the diffraction patterns were unsuccessful until it was demonstrated experimentally that nuarly all patterns taken at pressures above $51 \mathrm{kbar}$ were due to a mixtuie of two high pressure phases, $x^{\prime}-\mathrm{Ce}$ and $\mathrm{a}^{\prime \prime}-\mathrm{Ce}$. When the specimen was subjected to pressure cyclings some of the lines of the diffraction pattern became spotty while others remained smooth: as the cyclings proceeded the spott $\because$ lines gained in intensity while the smonth lines became weaker. Accordingly, one high pressure phase, $\left(r^{\prime}-\mathrm{C} e\right.$, associated with the spotty diffraction lines, showed appreciable crystal growth induced by the cycling process. while the se- cond phase. a"-('e, responsible for the smonth lines. thowed no noticeable increase in srystallite size.

large hysteresis ellects were observed. Thus. samples which had been subjected to high pressures showed the presence of the high pressure phases togethe with the a-phase in diffraction patterns taken at pressures as low as 27 kbar.

\section{THE STRUCTURE O' $\alpha \cdot-\mathrm{Ce}$}

Table Il compa:es diffraction data for $t$ wo of our patterns and the one ubserved by McWhan. Pattern A was taken at a piessure of 82 kbar. the pressure having been increased to this value in steps. All the diffraction lines of pattern $A$ were smooth. Pattern $B$ was taken of the same specimen at a pressure of is khar after many pressure cyclings. All the diffraction lines. except for the two very weak ones given in parentheses, became spotty and had to be ascribed to the coarsely cristalline ${ }^{\prime}$ '-phase which , clearly. is thr same phase that MciWhan reported.

McWhan's proposed hexagonal indexing is not acceptable: (1) Some of the lines of pattern $B$ cannot be explained. (2) One of the strongest reflections. (112). of the hcp structure with all atoms scattering in phase is not even observed. (3) Lines $\mathrm{S}$ $=171$ and $S=500$ correspond to the hexagonal reflection $(100)$ and $(110)$ with $\$$-values in the ratio $1: 3.00$, whereas the measurec ratio is $1: 2.93 \pm 0.02$.

However, as demonstrated in Tables II and III. all diffraction lines of the a'-Ce patterns can be satisfactorily explained in terms of a C-centered orthorhombic unit cell. Cell dimensions as deduced from the data of Table II are:

$$
\begin{aligned}
& \text { Pattern A: } \\
& \begin{aligned}
\mathrm{a}=3.009 \pm 0.005 \AA \\
\mathrm{b}=5.918 \pm 0.010 \AA \\
\mathrm{c}=5.145 \pm 0.010 \AA
\end{aligned}
\end{aligned}
$$

Pattern B:

$$
\begin{aligned}
& a=3.049 \pm 0.005 \AA \\
& b=5.988 \pm 0.010 \AA \\
& c=5.215 \pm 0.010 \AA
\end{aligned}
$$

Cell dimeissions as deduced from the data of 'Table III are:

$$
\begin{aligned}
\text { a-Ce: } & \\
\mathrm{a} & =4.677 \pm 0.004 \AA \\
\text { a'-Ce: } & \\
\mathrm{a} & =3.110 \pm 0.005 \AA \\
\mathrm{b} & =6.061 \pm 0.010 \AA \\
\mathrm{c} & =5.274 \pm 0.010 \AA
\end{aligned}
$$


TABLE I

VARLATION OF ATOMIC VOLUME WITH PRESSURE ${ }^{a}$

\begin{tabular}{|c|c|c|c|c|c|}
\hline \multirow[b]{2}{*}{$P$ (kbar) } & \multicolumn{2}{|c|}{$y-\mathrm{Ce}_{2}$} & \multicolumn{2}{|c|}{$\underline{\alpha-\mathrm{Ce}}$} & $\alpha^{\prime \prime}-\mathrm{Ce}$ \\
\hline & a $(\AA)$ & $y\left(\AA^{3}\right)$ & a. $(\AA)$ & $v\left(\AA^{3}\right)$ & $\mathrm{y}\left(\AA^{3}\right)$ \\
\hline 0 & 5. 164 & 34.43 & (4. 877 & $29.00)$ & $(26.26)$ \\
\hline 4,5 & 5. 104 & 33.24 & 4.831 & 28.19 & $\cdots$ \\
\hline 7.5 & 5.063 & 32.45 & 4.800 & 27.65 & $\cdots$ \\
\hline 10 & -- & $\cdots$ & 4.780 & 27.30 & $\cdots$ \\
\hline 20 & $\cdots$ & $\cdots$ & 4.714 & 26.19 & $\cdots$ \\
\hline 30 & $\cdots$ & $\cdots$ & 4.665 & 25.38 & -- \\
\hline 40 & $\cdots$ & $\cdots$ & 4.631 & $2 \dot{4} .83$ & $\cdots$ \\
\hline 50 & $\cdots$ & $\cdots$ & 4.604 & 24.40 & $\cdots$ \\
\hline 51 & $\cdots$ & $\cdots$ & 4.602 & 24.37 & 24.10 \\
\hline 56 & $\cdots$ & $\cdots$ & $\cdots$ & $\cdots$ & [23.91] \\
\hline 60 & $\cdots$ & $\cdots$ & $\ldots$ & $\cdots$ & 23.76 \\
\hline 70 & $\cdots$ & -.- & $-\cdot$ & $\cdots$ & 23.36 \\
\hline 80 & $\cdots$ & $\cdots$ & $\cdots$ & $\cdots$ & 22.98 \\
\hline 90 & $\cdots$ & $\cdots$ & $\cdots$ & $\cdots$ & 22.60 \\
\hline 100 & $\cdots$ & $\cdots$ & $\cdots$ & $\cdots$ & [22.22] \\
\hline
\end{tabular}

${ }^{a}$ Numbers given in parontheses a re extrapolated values. Numbers given in brackets a re experimental values (see Sec. II).

The observed volume and intensities require four cerium atoms per unit cell in positions $4 c$ o: the space group $\mathrm{Cmcm}$. These positions are $(000)$ $(1 / 21 / 20)+: \pm(0 \times 1 / 4)$ with $y \approx 1 / 10$. It was realized at this stage that the structure deduced for $a{ }^{\prime}-\mathrm{Ce}$ is of the $a-\mathrm{U}$ type first described by Jacob and Warren. 1: In fact. it is the first known example of this structure type other than uranicm itself.

Our data do not permit a precise determination of the parameter $y$. hence we will assume that it has the same value $y=0.105$ as found by Jacob and Warren for the $a-\mathrm{l}$ structure. however the accuracy is no better than $y=0.105 \pm 0.010$.

Calculated and observed intensities for $\alpha-L$ and "C $\mathrm{C} e$ are shown in Table IV. The calculated intensities are given as $I \propto|F / f|^{2} p$ where $F$ is the multiplicity. Since all angle-dependent factors are omitted, only neighboring reflections should be compared. There is evidence of some preferential orientation: reflections with small values of the index $\mathrm{L}$ appear with enhanced intensity, indicating that the orthorhombic c-axis tends to align with the incident heam which has the direction of maximum pressure.

Bond lengths in $\mathrm{at}^{\prime}-\mathrm{Ce}$ at $58 \mathrm{kbar}$ are:

$$
\begin{array}{rl}
\mathrm{Ce} \cdot 2 \mathrm{Ce} & 2.90 \pm 0.05 \AA \\
-2 \mathrm{Ce} & 3.05 \pm 0.01 \AA \\
-4 \mathrm{Ce} & 3.36 \pm 0.01 \AA \\
-4 \mathrm{Ce} & 3.49 \pm 0.06 \AA
\end{array}
$$

The bond angle for the iwo shortest bonds is $128 \pm$ $5^{\circ}$. and endless zig-zag chains of cerium atoms are formed in the c-direction. The bond angle for the two $n \in \times x$-shortest bonds is $180^{\circ}$, corresponding to endless straight chains along the a-axis.

\section{THE CRYSTAL STRUCTURE OF $\alpha "-$ Ce}

The diiiraction pattern of ${ }^{\prime \prime}$-Ce is quite similar to that of a-Ce. except that the fcc diffraction lines have been split into components. This close relationship is demonstrated in Table $V$ which presents the dat a from a diffraction pattern taken at $41 \mathrm{kbar}$. This diffraction pattern shows the presence of both a-Ce and $a "-C e$. Also shown in Table $V$ are the data from a single phase diffraction pattern of " "-Ce taken at $90 \mathrm{kbar}$.

The diffraction lines of $a "-\mathrm{Ce}$ correspond to a pseudo-cubic monoclinic body-centered structure with only two atoms per unit cell, as demonstrated by the indexings shown in Table $\mathrm{V}$. Cell dimensions deduced from the data of Table $V$ are:

$$
\begin{aligned}
& 41 \text { kbar pattern } \\
& \text { (1-Ce: } \\
& 3=4.629 \pm 0.006 \AA \\
& V=24.80 \AA^{3}
\end{aligned}
$$


TABLE II

DIFFRACTION DATA FOR $\alpha^{\prime-C e}$

Pattern A (82 kbar) Pattsm B (58 kbar)

$\underline{H K L}$

020

110

-.-

002

021

111

022

112

130

$-\cdots$

131

200

023

040

113

041

132

220

--.

202

221

004

042

222

133

024

114

043

150

151

223

240

241

134

152

310

060
Scalc Iobs $S_{\text {obs }}$

144

176

..- -.. -.-

191 vod $192^{a}$

223 s $223^{a}$

223 s $263^{b}$

335

366

464

-..

512

558

574

577

605

625

655

702

--

749

750 .

763

768

893

893

907

939

1006

1041

1089

1132
1135

1183

1227

1232

1292

1298 $\ldots$-..

m 366

$\cdots \quad 471^{b}$

$\begin{array}{ll}\text { Vw } & 471^{\mathrm{b}} \\ \text { SD } & 513^{\mathrm{a}}\end{array}$

$\begin{array}{ll}\text { SD } & 513 \\ \mathbf{w} & 557\end{array}$

vw 578

-. - -.

vwD $625^{a}$

-. -..

vwD $717^{b}$

mD $749^{a}$

-.. -..

-n - -

-...-

vw 897

... -..

942

-.

vw 1040

$\ldots \ldots$

vw 1134

- - - -

vw 1233

vw 1293
$S_{\text {calc }} I_{\text {obs }} S_{\text {obs }}$

McWhan

Iobs $S_{\text {obr }}$

.40 vw 138

171 s 171

..- (vw 182)

$186-\mathrm{m} \quad 187$

187

$\begin{array}{ccc}17 & 5 & 217 \\ --- & \text { (vw } & 252\end{array}$

326

357

452

$---$

498

543

558

562

589

608

638

684

729

730

743

747

869

870

883

914

980

1013

1060

1102

1105

1151

$\left.\begin{array}{l}1195 \\ 1199\end{array}\right\}$

1257

t 330

m 357

-.. -..

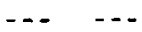

s 500

vw 542

-.. -..

$-\cdots \quad-\cdots$

vw 589

... $\quad .$.

vw 637

... -..

$--$

m 729

-.. -..

-.

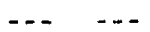

m 868

m... ...

$\ldots$

vw 1010

. 10

m 1106

$\ldots \ldots$

w $\quad 1197$

$\cdots \quad \cdots$

... $\quad . .$.

8 186

m 217

-.. -..

-.

vw 355

-.. -..

-..--

m 499

... ...

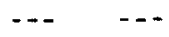

$\ldots$

n

$\cdots$

...

n...

… -.

w 725

vw $\quad 748$

-..

t 870

-.- -.-

-.

-.

t 1014

t 1103

...

t $\quad 1207$

w 1268

${ }^{a}$ Coincidence with prominent lines of $\alpha^{\prime \prime}-\mathrm{Ce}$.

$b_{\text {Diffraction lines of } \alpha "-C e \text {. }}$

a"-Ce:

$$
\begin{aligned}
& a=4.806 \pm 0.012 \AA \\
& b=3.194 \pm 0.006 \AA \\
& c=3.196 \pm 0.056 \AA \\
& s=92.18 \pm 0.40^{\circ} \\
& V=24.51 \AA^{3} \\
& a: b: c=1.508: 1: 1.001
\end{aligned}
$$

90 khar pattern

(r).Ce:

$\mathrm{a}=4.702 \pm 0.010 \AA$ $b=3.102 \pm 0.005 \AA$

$c=3.104 \pm 0.005 \AA$

$b=91.99 \pm 0.20 \AA$

$\mathrm{V}=22.62 \AA^{3}$

$a: b: c=1.516: 1: 1.001$

Were $i=90^{\circ}$ and the axial ratios $\sqrt{2}: 1: 1$, the monorlinic structure would become the fcc structure. 
TABLE III

DIFFRACTION DATA FOR $\alpha-\mathrm{Ce}+\alpha^{\prime}$-Ce AT 27 kbar

\begin{tabular}{|c|c|c|c|c|c|}
\hline \multirow[b]{2}{*}{ Iobs } & \multirow[b]{2}{*}{$S_{\text {obs }}$} & \multicolumn{2}{|c|}{$\alpha-c_{\Omega}$} & \multicolumn{2}{|c|}{$x^{\prime}-c e$} \\
\hline & & HKLL & $s_{\text {calc }}$ & HKL & $\mathbf{s}_{\text {calc }}$ \\
\hline$v w$ & 138 & -. & $\cdots$ & 020 & 138 \\
\hline 8 & 165 & -- & $\cdots$ & 110 & 165 \\
\hline m & 175 & 111 & 173 &.- & -- \\
\hline$s$ & 183 & -- &.- & $\begin{array}{l}002 \\
021\end{array}$ & $\begin{array}{l}182 \\
183\end{array}$ \\
\hline 8 & 209 & $\cdots$ & $\cdots$ & 111 & 210 \\
\hline wm & 231 & 200 & 231 & $\cdots$ & .. \\
\hline vw & $248^{a}$ & $\cdots$ & $\cdots$ & $\cdots$ & $\cdots$ \\
\hline $\mathrm{m}$ & 347 & $\cdots$ & $\cdots$ & 112 & 347 \\
\hline $\mathbf{w}$ & 460 & 220 & 462 & $\cdots$ & $\cdots$ \\
\hline $\mathrm{ms}$ & 486 & $\cdots$ & $\cdots$ & 131 & 485 \\
\hline $\mathbf{v w}$ & 518 & $\cdots$ & $\cdots$ & 200 & 522 \\
\hline$v w$ & 545 &.- & $-\cdot$ & $\begin{array}{l}023 \\
040\end{array}$ & $\begin{array}{l}546 \\
550\end{array}$ \\
\hline vow & 592 & $\cdots$ & $-\cdot$ & 041 & 595 \\
\hline wm & 634 & 311 & 635 & $\cdots$ & 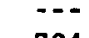 \\
\hline $\mathrm{mD}$ & 703 & 222 & 693 & $\begin{array}{l}202 \\
221\end{array}$ & 704 \\
\hline W & 847 &.-- & $\cdots$ & 133 & 849 \\
\hline $\mathbf{w}$ & 995 & --- & $\cdots$ & 150 & 990 \\
\hline vw & 1074 & $\cdots$ & -- & $\begin{array}{l}240 \\
223\end{array}$ & $\begin{array}{l}1072 \\
1069\end{array}$ \\
\hline vw & 1168 & $\cdots$ & $-\cdot$ & 152 & 1172 \\
\hline
\end{tabular}

Diffraction patterns of cerium metal taken at 56 kbar and at $100 \mathrm{kbar}$ have been published by Schaulelherger and Merx. 8 Detailed analysis of their data shows that the bulk of their sample is $c "$ "Ce. Table VI gives the S-values. obtained from their published $2 t$-values, for all lines due to the $\alpha "$-phase (up to $S=1064$ ). The agreement between observed and calculated $S$-values is excellent. The unit cell dimensions deduced from their patterns are:

$56 \mathrm{kbar}$ pattern

$$
\begin{aligned}
& a=4.762 \pm 0.006 \AA \\
& b=3.170 \pm 0.005 \AA \\
& c=3.169 \pm 6.005 \AA \\
& b=91.73 \pm 0.15^{\circ} \\
& b=23.91 \AA
\end{aligned}
$$

100 kbai pattern

\begin{tabular}{|c|c|c|c|c|c|}
\hline \multicolumn{3}{|c|}{56 kbar pattern } & \multicolumn{3}{|c|}{100 kbar patrern } \\
\hline Line No. & $I_{\text {obs }}$ & $\underline{\mathbf{S}_{\text {obs }}}$ & Line No. & $\underline{I_{\text {obs }}}$ & $S_{\text {obs }}$ \\
\hline $4^{*}$ & w & 268 & & & \\
\hline $5^{*}$ & w & 294 & $4^{*}$ & $\mathrm{~m}$ & 308 \\
\hline & & & $5^{*}$ & $v w$ & 385 \\
\hline 6 & vw & 387 & $6^{*}$ & $w$ & 409 \\
\hline 7 & $v w$ & 396 & $7^{*}$ & $w$ & 421 \\
\hline & & & 8 & $w$ & 455 \\
\hline 17 & $r w$ & 803 & 18 & vw & 837 \\
\hline & & & 19 & $\mathrm{vw}$ & 845 \\
\hline 18 & Ww & 847 & 20 & vw & 892 \\
\hline 20 & $\mathrm{~m}$ & 920 & 22 & wv & 769 \\
\hline
\end{tabular}

$$
\begin{aligned}
& 1=4.686 \pm 0.006 \AA \\
& b=3.073 \pm 0.005 \AA \\
& c=3.089 \pm 0.005 \AA \\
& s=92.69 \pm 0.15^{\circ} \\
& v=22.22 \AA
\end{aligned}
$$

Btlow is a list of diffraction lines reported by Schaufelberger and Merx which we have never observed and which remain unexplained

The lines marked by asterisks were attributed by Schaufelberger and Merx to estraneous, but unidentified, material in the pressure cell.

Since the positions of the two atoms in the $\alpha^{\prime \prime}-\mathrm{Ce}$ structure are $(000)(1 / 21 / 21 / 2)$, the calculated intensities cie directly proportional to the multiplicity $p$. In Table VII the values of $p$ and the observed intensities are compared. As in $a^{-}$-Ce there is evidence of prefarred orientation. For five of our six samples and the two patterns of Schaufelberger and Merx, the intensity of a reflection ( $\mathrm{HKL}$ ) is enhanced relative

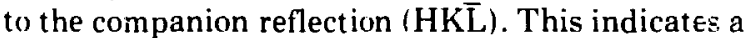
tendency of the plane ( $10 \overline{1})$ to line up normal to the incident beam. However. in our sixth sample. 17709 . the $(\mathrm{HK} \overline{\mathrm{L}})$ component is enhanced. indicating a tendency of the (101) plane to be oriented normal to the incident beam.

Bond lengths in the $\mathrm{c}^{\prime \prime}-\mathrm{Ce}$ structure at $56 \mathrm{kbar}$ are:

$$
\begin{array}{cl}
\mathrm{Ce}-2 \mathrm{Ce} & 3.169 \pm 0.005 \AA \\
-2 \mathrm{Ce} & 3.170 \pm 0.05 \AA \\
-4 \mathrm{Ce} & 3.235 \pm 0.010 \AA \\
-4 \mathrm{Ce} & 3.305 \pm 0.010 \AA
\end{array}
$$

Thus. as in "i-Ce. there are four short and eight longer bonds. The short bonds form endless straight chains along the b-axis and along the c-axis.

\section{DISCUSSION}

The variation of unit cell dimensions of " $1 \cdot C e$ and ""-Ce with pressure is given in Table VIII. The two high pressure phases have the same volume within 
TABLE IV

$$
\text { INTENSTIIES FOR } \alpha-U \text { AND } \alpha^{\prime}-\mathrm{Ce}
$$
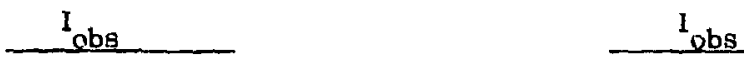

$\underline{H K L} \quad \underline{\text { cala }} \underline{\alpha-U} \quad \underline{\alpha}-\mathrm{Ce}$

020

110

002

no 1

111

022

112

130

131

200

023

040

113

041

132

202
0.2

5.0

4.0

7.5

6.0

0.5

10.0

1.3

13.5

4.0

7. 5

3.1

6. 0

1. 9

2. 5

0.5

\begin{tabular}{|c|c|}
\hline $\mathbf{v}$ & vw \\
\hline $\mathbf{s}$ & $\mathbf{s}$ \\
\hline $\begin{array}{l}\mathbf{s} \\
\mathbf{s}\end{array}$ & $m$ \\
\hline $\mathbf{s}$ & $\mathbf{s}$ \\
\hline$v W$ & $t$ \\
\hline $\mathbf{g}$ & $m$ \\
\hline$v W$ & $\cdots$ \\
\hline $\mathbf{s}$ & $\mathbf{s}$ \\
\hline $\mathbf{w}$ & vw \\
\hline $\left.\begin{array}{l}\mathbf{m} \\
\mathbf{w}\end{array}\right)$ & \\
\hline $\mathbf{m}$ & $\mathbf{v}$ \\
\hline vw & $v w$ \\
\hline$w$ & vw \\
\hline $\mathbf{v w}$ & $-\infty$ \\
\hline
\end{tabular}

HKL I calc

$\begin{array}{rr}202 & 8.0 \\ 221 & 15.0 \\ 004 & 4.0 \\ 042 & 6.1 \\ 222 & 1.0 \\ 133 & 13.5 \\ 024 & 0.5 \\ 114 & 10.0 \\ 043 & 1.9 \\ 150 & 7.8 \\ 151 & 0.4 \\ 223 & 15.0 \\ 240 & 6.1 \\ 241 & 3.7 \\ 134 & 2.5 \\ 132 & 15.6\end{array}$

$\mathrm{s} \mid \mathrm{m}$

m) vw

\begin{tabular}{l|l}
$\mathrm{vw}$ & $\mathrm{m}$
\end{tabular}

$\alpha-U \quad \alpha^{\prime} C e$

$\begin{array}{ll}v w & \cdots \\ m & v w \\ v w & -\cdots \\ w m & v w \\ n i l & \cdots \\ m & m \\ w & m \\ v w & \cdots \\ v w \\ m\end{array}$

TABLE V

DIFFRACTION DATA FOR $\alpha$-Ce $+\alpha^{\prime \prime}$-Ce AT 41 kbar AND FOR

$\alpha$ ". Ce AT 90 kbar

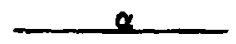

HKSI S sale

$111 \quad 177$

$200 \quad 236$

220

301
002
310
301

311

222

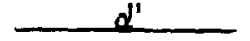

IISL Scalc

$\left\{\begin{array}{l}10 \mathrm{i} \\ 110 \\ 101\end{array}\right.$

172
179
185

$\left(\begin{array}{cc}200 & 219\end{array}\right.$

1011

$\left\{\begin{array}{l}211 \\ 211 \\ 020 \\ 002\end{array}\right.$
$\left\{\begin{array}{l}301 \\ 310 \\ 301 \\ 11 \overline{2} \\ 12 \overline{1} \\ 121 \\ 112\end{array}\right.$

112

$\{220$

248

454

479

495

617

635

667 )

$\left.\begin{array}{l}680 \\ 686 \\ 689\end{array}\right)$

714

739 $\alpha+\alpha "(41 \mathrm{kbar})$

$\alpha^{\prime \prime}(90 \mathrm{kbar})$

$\perp$ Sobs $S_{\text {calc }} I \quad S_{\text {obs }}$

$\begin{array}{lllll}\text { vw } & 172 & 182 & \text { vw } & 180\end{array}$

vs $\quad 177$

188
194 vs 188

m 219

$229 \quad$ w $\quad 227$ m 248

w 454

m 474

w 495

WD 609

wD $\quad 647$

262 vs 262

479 w- 479

$505 \quad w+505$

$\left.\begin{array}{l}525 \\ 525\end{array}\right\} \quad w^{-} \quad 525$

$628 \quad \ldots \quad \ldots$

646 w 646

664 ...

$\begin{array}{lllll}\text { WD } & 647 & & & \\ & & 701 \\ & & 707 & \text { w } & 703 \\ \text { wD } & 680 & 725 & \text { w } & 721 \\ & & 730 & \ldots & \ldots \\ \ldots & \ldots & 754 & \text { w } & 755 \\ \ldots & \ldots & 778 & \ldots & \ldots\end{array}$


INTERPRETATION OF THE DIFFRACTION DATA

REPORTED BY SCHAUFELBERGER AND MEIXX

\begin{tabular}{|c|c|c|c|c|c|c|}
\hline \multirow[b]{2}{*}{$\underline{H K L}$} & \multicolumn{3}{|c|}{$56 \mathrm{kbar}$} & \multicolumn{3}{|c|}{100 kbar } \\
\hline & $\mathrm{s}_{\text {calc }}$ & I abs & $S_{\mathrm{obs}}$ & $\mathrm{s}_{\text {calc }}$ & I obs & $\underline{S_{\text {obs }}}$ \\
\hline $10 \overline{1}$ & 177 & & & $18 ?$ &.- & - . \\
\hline 110 & 181 & vs & 181 & 192 & vs & 192 \\
\hline 101 & 187 & & & 198 & vs & 198 \\
\hline 200 & 223 & $\mathrm{~m}$ & 222 & 231 & $\mathrm{w}$ & $231^{a}$ \\
\hline 011 & 252 & $\mathrm{~s}$ & 252 & 267 & vs & 267 \\
\hline $21 \overline{1}$ & 464 & w & 464 & 481 & $v w$ & 484 \\
\hline 211 & $\$ 35$ & $\mathrm{~m}$ & 486 & 513 & $\mathbf{s}$ & 514 \\
\hline 002 & 503 & $\varepsilon$ & $50 ?$ & 5301 & $s$ & 52 \\
\hline 020 & 5031 & $\varepsilon$ & & $536\}$ & & \\
\hline 301 & 612 & -.. & $\cdots$ & 627 & $\ldots$ & $\ldots$ \\
\hline 310 & 627 & w & 627 & 653 & $w$ & 653 \\
\hline 301 & 643 & $w$ & 641 & 676 & $w$ & 679 \\
\hline 112 & 675 & $=$ & 670 & 706 & ... & $\cdots$ \\
\hline $12 \bar{i}$ & $679\}$ & $\mathbf{s}$ & 679 & 718 & $\varepsilon$ & 719 \\
\hline 121 & 689 & & 680 & 734 & & \\
\hline 112 & $695\}$ & $\mathrm{s}$ & 689 & 738 & vs & 736 \\
\hline 202 & 706 & ... & $\cdots$ & $729)$ & & \\
\hline 220 & 726 & $\mathrm{~m}$ & 727 & 767 & $\mathbf{w}$ & 764 \\
\hline 202 & 747 & $\mathrm{vN}$ & 747 & 793 & $\mathbf{w}$ & 792 \\
\hline 400 & 892 & $w$ & 893 & 922 & $\mathrm{vw}$ & 922 \\
\hline 022 & 1006 & $\mathrm{w}$ & 1005 & 1066 & $\mathrm{~m}$ & 1064 \\
\hline
\end{tabular}

experimental error. However, there is a small volume change (of $-\Delta V / N=0.011$ ) when the $a$ phase is transformed to the $a$ - or $(a$ "-phase.

Nearly all of the diffraction patterns taken at pressures above il kbar show the presence oi both $a^{\prime}-\mathrm{Ce}$ ard $a "-\mathrm{Ce}$. However, the transition $a "-\mathrm{Ce}$ to "r-Ce proceeds at a very slow rate under constant pressure. Thus, one specimen was held at a pressure of 95 kbar for 10 days without a measurable change in the relative proportion of the two phases. Pressure cycling does, however, induce the $a^{\prime \prime} \rightarrow a^{\prime}$ transition. This ohservation is the only basis for our conclusion that the a'-phase is the stable form and the $"$ "-phase the metastable form of cerium metal at liigh pressures. The only single-phase diffraction patterns of " "Ce were obtained when the pressure was raised in one quick step from its room value to 90 or 96 khar. It is probable that a very slow rate of pressure increase near the transformation point will favor the formation of " $"$ '-Ce.

The transformation a . $a$ " involves only small shifts in the relative atomic positions $(\sim 0.1 \AA)$ so that a single crystallite of 1 -Ce should be transformea into a single crystallite of $a^{*}$-Ce. The $a \rightarrow a^{\prime}$. or $a^{\prime \prime}$ . " transformation. on the other hand. involves a major structural reorganization. The $a-a$ " phase change can probably be characterized as a second order transformation. but there is, as mentioned above, a small. discontinuous volume change.

The ohserved variation of atomic volume with pressure for a-Ce is shown in Table $I$ and Fig. 1. Analysis of the data shows a rapid decrease in the value of the compressibility $k$ from 7.5 to $51 \mathrm{kbar}$. and hence also in the extrapolated value of atomic volume $V_{i 1}$ at zero pressure. Results of this analysis are shown in Table IX. The same value $\mathrm{K}=1.7 \mathrm{x}$ $10-3 / \mathrm{kbar}$ is obtained for $1-\mathrm{Ce}$ in the range $40 \mathrm{to} 51$ kbar. for $a^{-}-\mathrm{Ce}$ in the range 58 to $95 \mathrm{kbar}$. and for " -Ce in the range 56 to $100 \mathrm{kbar}$.

It is convenient to detine the metallic radius $\mathrm{R}$ for 12 coordination in terms of the atomic volume per atom $V$ by the equation 13

$R \equiv\left(V^{1 / 3}\right) /(2016)$ 
TABLE VII

$\alpha "$-Ce INTENSITIES

\begin{tabular}{|c|c|c|c|c|c|}
\hline \multirow[b]{2}{*}{ HKL } & \multicolumn{4}{|c|}{$I_{\text {obs }}$} & \multirow[b]{2}{*}{$\begin{array}{l}65 \mathrm{kbar} \\
\text { Pattern of } \\
\text { Specimen } 17709 \mathrm{a}\end{array}$} \\
\hline & $\begin{array}{l}\text { Multi- } \\
\text { plicity }\end{array}$ & $\begin{array}{l}90 \mathrm{kbar} \\
\text { Pattern of } \\
\text { Table V } \\
\end{array}$ & $\begin{array}{l}56 \text { kbar } \\
\text { Pattern of } \\
\text { Table VI } \\
\end{array}$ & $\begin{array}{l}100 \mathrm{kbar} \\
\text { Pattern of } \\
\text { Table VI }\end{array}$ & \\
\hline $10 \bar{i}$ & 2 & $\mathbf{v w}$ & & $\ldots$ & $s^{b}$ \\
\hline 110 & 4 & ve & vs & vs & $s^{b}$ \\
\hline 101 & 2 & vs & & $\because$ ? & \\
\hline 200 & 2 & $\mathbf{w}$ & $\mathrm{m}$ & $\mathbf{w}$ & $s^{b}$ \\
\hline $01 \underline{1}$ & 4 & vs & $\mathbf{s}$ & vs & $\mathrm{m}$ \\
\hline $21 \overline{1}$ & 4 & w- & $\mathbf{w}$ & $V \boldsymbol{N}$ & $\mathrm{m}$ \\
\hline 211 & 4 & wt & $\mathrm{m}$ & s & $m$ \\
\hline 002 & 2 & & & & 111 \\
\hline 020 & 2 & $\mathbf{w -}$ & $\mathbf{S}$ & $\mathbf{s}$ & vwt \\
\hline $30 \overline{1}$ & 2 & $\cdots$ & $\cdots$ & $\cdots$ & $w^{+}$ \\
\hline 310 & 4 & w & $\mathbf{w}$ & $\mathbf{w}$ & $w^{+}$ \\
\hline 301 & 2 & $\cdots$ & $w$ & $w$ & $\cdots$ \\
\hline $11 \overline{2}$ & $4 \mid$ & & & $\cdots$ & \\
\hline $12 \overline{1}$ & 41 & $\mathbf{w}$ & $\mathbf{s}$ & s 1 & $V W$ \\
\hline 121 & 41 & VO & s & & \\
\hline 112 & 41 & $\mathbf{W}$ & s & vs & wD \\
\hline $20 \overline{2}$ & 2 & $\cdots$ & -- & & \\
\hline 220 & 4 & $\mathbf{w}$ & $\mathrm{m}$ & $\mathbf{w}$ & vwt \\
\hline 202 & 2 &.- & vw & $w$ & $\cdots$ \\
\hline 400 & 2 & -- & $\mathbf{w}$ & $v w$ & $\mathbf{w}$ \\
\hline 022 & 4 & $\cdots$ & $\mathrm{w}$ & $\mathrm{m}$ & $\mathrm{vw}$ \\
\hline
\end{tabular}

3with unusual preferred orientation effect.

bCoincidence with $\alpha^{\prime}$-Ce lines.

Paulinglt was the first to point out that the metallic radius of cerium in $y-C e$ is smaller than expected from a comparison with typically trivalent $4 \mathrm{f}$ metals, and he suggested a metalic valence $\mathrm{v}=3.2$ for cerium in,$-\mathrm{Ce}$. The expected value for the metallic radius of cerium for $v=3.00$ is $R=1.851 \AA$. On the other hand, when cerium is fully tetravalent. i.e.. a nember of the series of d-elements Ti-Zr-CeTh, the estimated metallic radius is $1.672 \AA .^{15}$ Table IX shows that the metallic radius of zerium of all three phases, $c^{\prime}, c^{*}$, and $c^{\prime \prime}$, extrapolated to room pressure from $50 \mathrm{kbar}$ and above, agrees with the predicted value for $v=4.00$. Indeed, the sinall value for the compressibility of $K=1.7 \times 10^{-3} / \mathrm{kbar}$, observed for pressures above $50 \mathrm{kbar}$. also indicates full tetravalency for cerium.

\section{ACKNOWLEDGMENT}

We are indebted to Marion Gibbs for measuring some of the diffraction patterns.

\section{REFERENCES}

1. F. H. Ellinger and W. H. Zachariasen. "Struciure of Cerium Metal at High Pressure." Phys. Rev. Lett. 32. 773-774 (1974).

2. A. W. Lawson and T. Y. Tang, "Concerning the High Pressure Allotropic Modification of Cerium," Phys. Rev. 76. 301 (1949).

3. W. H. Zachariasen. quoted by Lawson and Tang in Ref. 2, 1949.

4. P. W. Bridgman. "The (Electrical) Resistance of 72 Elements. Alloys and Compounds to 100,000 kg/cm?." Proc. Am. Acad. Arts Sci. 81, $169-251$ (1952).

5. R. A. Stager and H. G. Drickamer, "Effect of Pressire and Temperature on the Electrical Resistance of Eleven Rare-Furth Metals," Phys. Rev. 133A, 830-835 (1964). 
TABLE VIII

UNIT CELL DIMENSIONS FOR $\alpha^{\prime}-\mathrm{Ce}$ AND $\alpha^{\prime \prime}-\mathrm{Ce}^{\mathrm{a}}$

$\alpha \cdot-\mathrm{Ce}$

\begin{tabular}{|c|c|c|c|c|c|c|c|}
\hline \multirow[b]{2}{*}{$\mathrm{P}(\mathrm{kbar})$} & \multirow[b]{2}{*}{$-\mathrm{a}(\dot{A})$} & \multirow[b]{2}{*}{$b(A)$} & \multirow[b]{2}{*}{$c(A)$} & \multirow[b]{2}{*}{$B$ (jeg) } & \multirow[b]{2}{*}{$Y\left(A^{3}\right)$} & \multicolumn{2}{|c|}{ Second Phase } \\
\hline & & & & & & Bhase & $V\left(A^{3}\right)$ \\
\hline 27 & $3.110(5)$ & $6.061(10)$ & $5.274(10)$ & $\ldots$ & 24.85 & $\alpha$ & 25.60 \\
\hline 49 & $3.081(5)$ & 5. $995(10)$ & 5. $225(10)$ & $\cdots$ & 24.13 & $\alpha$ & 24.46 \\
\hline 58 & $3.049(5)$ & 5. $998(10)$ & $5.215(10)$ & $\ldots$ & 23.84 & $t \alpha^{\prime \prime}$ &.-- \\
\hline 65 & $3.036(5)$ & 5. $956(10)$ & 5. $183(10)$ & $\ldots$ & 23.43 & $\alpha^{\prime \prime}$ & 23.55 \\
\hline 82 & $3.009(5)$ & $5.918(10)$ & $5.145(10)$ & ... & 22.90 & $\alpha^{\prime \prime}$ & 22.87 \\
\hline 95 & $2.993(5)$ & $5.868(10)$ & $5.103(10)$ & ... & 22.40 & $\boldsymbol{\alpha}^{\prime \prime}$ & 22.46 \\
\hline
\end{tabular}

$$
\alpha "-\mathrm{Ce}
$$

\begin{tabular}{|c|c|c|c|c|c|c|c|}
\hline \multirow[b]{2}{*}{ e(kbar) } & \multirow[b]{2}{*}{$a(\dot{A})$} & \multirow[b]{2}{*}{$b(\dot{A})$} & \multirow[b]{2}{*}{$c\left(\dot{A}_{2}\right)$} & \multirow[b]{2}{*}{ B (deg) } & \multirow[b]{2}{*}{$V\left(A^{3}\right)$} & \multicolumn{2}{|c|}{ Second Phase } \\
\hline & & & & & & Phase & $y\left(\dot{a}^{3}\right)$ \\
\hline 39 & $4.815(12)$ & $3.204(6)$ & $3.205(6)$ & $3 i .23(40)$ & 24.71 & $\alpha$ & $2 \dot{4} .8 B$ \\
\hline 41 & $4.806(12)$ & $3,1 \leqslant 4(6)$ & $3.196(6)$ & $92.18(40)$ & 24.51 & $\alpha$ & 24,80 \\
\hline 56 & $4.762(6)$ & $3.170(5)$ & $3.169(5)$ & $91.73(15)$ & 23.91 & $\cdots$ & $\cdots$ \\
\hline 65 & $4.773(10)$ & $3.114(6)$ & $3.172(6)$ & $92.33(20)$ & 23.55 & $\alpha^{\prime}$ & 23,43 \\
\hline 82 & $4.762(15)$ & $3.099(6)$ & $3.102(6)$ & $92.51(40)$ & 22.87 & $\alpha^{\prime}$ & 22.90 \\
\hline 87 & $4.732(12)$ & $3.099(6)$ & 3. $102(6)$ & $92.49(30)$ & 22.72 & t $\alpha$ & $\cdots$ \\
\hline 90 & $4.702(10)$ & $3.102(5)$ & $3.104(5)$ & $91.99(20)$ & 22.62 & $\cdots$ & $\cdots$ \\
\hline 95 & $4.733(15)$ & $3.081(6)$ & $3.084(6)$ & $92.64(40)$ & 22.46 & $\alpha^{\prime}$ & 22.40 \\
\hline 96 & $4.685(12)$ & $3.090(6)$ & $3.092(5)$ & $91.97(30)$ & 22.37 & $\cdots$ & -- \\
\hline 100 & $4.686(6)$ & $3.073(5)$ & $3.080(5)$ & $92.69(15)$ & 22.22 & -- & $\cdots$ \\
\hline
\end{tabular}

${ }^{a_{\text {Estimated }}}$ error in last decimal place given in parentheses.

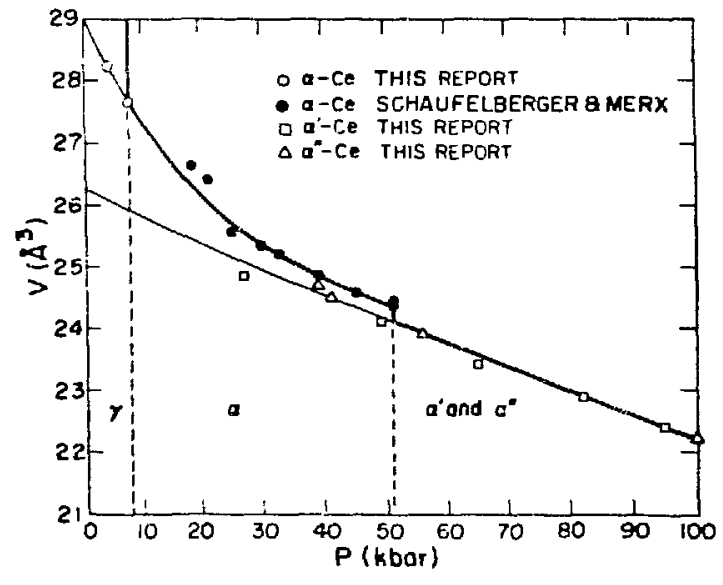

Fig. 1.

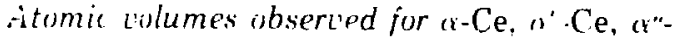
Ce.
6. .J. Wittig, "Superconductivity of Cerium under Pressure." Phys. Rev. Lett. 21, 1250-1252 (1968).

7. E. King, J. A. Lee. I. R. Harris, and 'T F. Smith. "New Phase Boundary for Cerium." Pnys. Rev. Bl, 1380-1381 (1970).

8. P. L. Schaufelberger and H. Merx. "Structural Investigations on Cerium." Proc. 4th Int. Corf. on High Pressure, Kyoto, 1974. pp. 222-227.

9. E. Franceschi and G. L. Olcese. "A New Allotropic Form of Cerium Due to its Transition under Pressure to the Tetravelent State," Phys. Rev. Latt. 22, 1299-1:300 (15.5).

10. D. B. Mcthan, "Structure of Cerium above 50 kbar." Phys. Rev. B1. 2826 (1970). 


\begin{tabular}{|c|c|c|c|c|c|}
\hline Phase & P (kbar) & $\mathrm{K}\left(10^{-3} / \mathrm{kbarl}\right.$ & $\mathrm{V}_{0}\left(\mathrm{~A}^{3}\right)$ & R. $(\AA)$ & $v$ \\
\hline Ideal & 0 & --- & 35.89 & 3.851 & 3.00 \\
\hline$\gamma-\mathrm{Ce}$ & 0 & $\cdots$ & 34.43 & 1.825 & 3.15 \\
\hline$\alpha-\mathrm{Ce}$ & 0 & $\ldots$ & 29.00 & 1.724 & 3.72 \\
\hline$\alpha-\mathrm{Ce}$ & 7. 5- 25 & 4.1 & 28.52 & 1.714 & 3.77 \\
\hline$\alpha-\mathrm{Ce}$ & $25-40$ & 2.3 & 27.27 & 1.689 & 3.90 \\
\hline$\alpha-\mathrm{Ce}$ & $40-51$ & 1.7 & 26.58 & 1. 675 & 3. 97 \\
\hline$\alpha^{1-C e}$ & $58-95$ & 1.7 & 26.29 & 1.669 & 4.00 \\
\hline$\alpha^{\prime \prime}-\mathrm{Ce}$ & $56-100$ & 1.7 & 26.26 & 1.668 & 4.00 \\
\hline
\end{tabular}

11. W. A. Bassett, T. Takahashi. and P. W. Stook, "X-ray Diffraction and Optical Observations on Crystalline Solids up to 300 kbar." Rev. Sci. Instrum. 38, 3i-42 (1967).

12. C. W. Jacob and B. F. Warren, "The Crystalline Structure of ['ranium." J. An. Chem. soc. 59. 2588-2591 (1937).

13. W. H. Zachariasen. "Metallic Radii and Electron Configurations of the 5f-6d Metals." J. Inorg. Nucl. Chem. 35, 3487-3497 (1973).
14. I. Pauling, "Atomic Radii and Interatomic Distances in Metals," J. Am. Chem. Soc. 69, 542-55;3 (1947).

15. W. H. Zachariaser. "The Structure of Plutonium Metal," Proc. Plutonium Chemistry Symposium, February 18. 1963. Univ. of Chicago and Aronne National Laboratory. pp. 12-15. 